Revista Mídia e Cotidiano

ISSN: 2178-602X

Artigo Seção Livre

Volume 15, Número 2, maio/ago. de 2021

Submetido em: 13/12/2020

Aprovado em: 20/04/2021

\title{
O novo coronavírus e a condição da banalidade do mal
}

\section{The new coronavirus and the condition of banality of evil}

\section{El nuevo coronavirus y la condición de la banalidad del mal}

Muriel Emídio Pessoa do AMARAL ${ }^{1}$

\section{Resumo}

A proposta deste artigo é reconhecer o sentido da banalidade do mal, desenvolvido por Hannah Arendt (1999), em acontecimentos contemporâneos ocorridos no Brasil durante a pandemia do novo coronavírus. De acordo com a autora, o mal é banal porque é praticado por pessoas convencionais que se abstiveram de pensar politicamente. A partir dessa ideia, por meio da análise de matérias jornalísticas divulgadas pelo site Catraca Livre, o artigo apresenta reflexões sobre as manifestações contra a quarentena e isolamento social e físico sugeridos pela Organização Mundial da Saúde (OMS) para conter o avanço da doença. As manifestações ocorreram na cidade de São Paulo e ainda apoiaram a figura do presidente brasileiro Jair Bolsonaro.

Palavras-chave: Coronavírus. Banalidade do mal. Política.

\begin{abstract}
The purpose of this article is to recognize the sense of the banality of evil, developed by Hannah Arendt, in contemporary events that occurred in Brazil during the pandemic of the new coronavirus. According to the author, evil is banal because it is practiced by conventional people who refrained from thinking politically, thus, evil arises. Based on that idea this article analyses news published by Catraca Livre Brazilian site and presents reflections on the demonstrations against quarantine and social and physical isolation, suggested by the World Heath Organizations (WHO) to contain the spread of infections. The demonstrations took place in the city of São Paulo and supported the figure of Brazilian President Jair Bolsonaro.
\end{abstract}

Keywords: Coronavirus. Banality of evil. Politics.

\footnotetext{
1 Professor colaborador do Departamento de Jornalismo da Universidade Estadual de Ponta Grossa (UEPG), pós-doutorado em Jornalismo pela Universidade Estadual de Ponta Grossa (UEPG). Doutor e Mestre em Comunicação pela Universidade Estadual Paulista (UNESP/Bauru), doutorado sanduíche em Estudos Culturais pela Universidade de Aveiro (Portugal). E-mail: murielamaral@yahoo.com.br. ORCID: 0000-0003-3069-6697.
} 
Resumen

El propósito de este artículo es reconocer el sentido de la banalidad del mal, desarrollado por Hannah Arendt, en los hechos contemporáneos ocurridos en Brasil durante la pandemia del nuevo coronavirus. Según la autora, el mal es banal porque lo pracitcan personas convencionales que se abstienen de pensar políticamente, por lo que surge el mal. Partiendo de esta idea, al analizar los artículos publicados por el sitio web Catraca Livre, el artículo presenta reflexiones sobre las manifestaciones contra la cuarentena y el aislamiento social y físico, sugeridos por la Organización Mundial de la Salud (OMS) para contener la propagación de infecciones. Las manifestaciones tuvieram lugar em la ciudad de São Paulo y seguían protestando en apoyo a la figura del presidente brasileño Jair Bolsonaro.

Palabras clave: Coronavirus. Banalidad del mal. Política.

\section{Introdução}

Este texto faz parte de uma pesquisa de pós-doutorado que investiga a representação de vidas que são compreendidas como descartáveis do espaço público. Neste artigo, a pesquisa avança para reconhecer que a ideia do mal banal, desenvolvida por Hannah Arendt (1999), pode ser reconhecida em acontecimentos veiculados pelo jornalismo tendo como recorte o cenário pandêmico causado pelo novo coronavírus no Brasil. A noção de banalidade do mal apresentada por Arendt discorre que o mal é reproduzido por pessoas convencionais e que se espalha facilmente porque é desprovido de reflexão política. A percepção foi desenvolvida por ela após acompanhar o julgamento de Adolf Eichmann, um funcionário nazista que atuou no Holocausto, acontecimento que será relatado ao longo do texto. Entretanto, para a análise atual, sai de cena o sujeito burocrata e vêm à luz pessoas comuns que, em grande medida, ofereceram suporte para o desenvolvimento do mal banal quando negligenciaram deliberadamente os alertas da ciência para enfrentar a Covid-19 e não respeitaram o movimento de luto.

Se a pandemia é um acontecimento, porque rompe com o cotidiano, as manifestações contemporâneas de um mal banal não deixam de ser um acontecimento porque nasceram de um fato ocorrido (a própria pandemia) e reverberam no tecido social até produzirem sentidos acerca dos afetos e signos culturais que estão em circulação e que refutam os avanços científicos e políticos. Assim, o texto trava diálogos entre a tese de Hannah Arendt (1999) e a ideia de acontecimento (FRANÇA, 2012; ARENDT, 2018), 
acerca do objeto escolhido para análise, e defende que o jornalismo explicitou a ocorrência do mal banal durante a pandemia do novo coronavírus.

Para alcançar esse objetivo, o texto recorreu a duas matérias veiculadas, entre os dias $11^{2}$ e $13^{3}$ de abril de 2020, pelo site Catraca Livre ${ }^{4}$, para dissertar sobre a fragmentação do espaço público, conforme pensada por Arendt (2018). Mesmo apresentando as matérias veiculadas no site Catraca Livre, a pesquisa encontrou outros veículos que também fizeram a cobertura do acontecimento em tela ${ }^{5}$. A intenção de apontar a existência de outras fontes de consulta sobre o acontecimento solidifica a ideia de que as manifestações apresentaram relevância pública e promoveram outros acontecimentos vindouros como o negacionismo científico e o questionamento quanto à necessidade e a importância da vacinação.

O negacionismo se manteve enquanto afeto não apenas no Brasil, a despeito de no país haver resultados mais dramáticos como o alto número de óbitos e infecções ${ }^{6}$, mas em outros países, como Estados Unidos (durante a gestão de Donald Trump), Turquemenistão e Bielorrússia, onde houve demonstrações negacionistas, tanto da população quanto de governantes.

As reflexões apresentadas na tessitura deste artigo não pretendem induzir ao pensamento de que as práticas de jornalismo adotadas pelo site ofereceram suporte às manifestações. Em vez disso, evidenciam contornos e representações do mal banal que estão em circulação. As matérias selecionadas relatam as manifestações públicas

${ }^{2}$ Disponível em: https://catracalivre.com.br/cidadania/manifestantes-pro-bolsonaro-travam-ambulanciasem-ato-na-paulista/. Acesso em: 25 nov. 2020.

3 Disponível em: https://catracalivre.com.br/cidadania/bolsonaristas-tiram-sarro-das-1-223-mortes-porcoronavirus-no-brasil/. Acesso em: 25 nov. 2020.

${ }^{4} \mathrm{O}$ site foi desenvolvido em 2008 pela iniciativa do jornalista Gilberto Dimenstein para abordar, num primeiro momento, iniciativas culturais gratuitas. Entretanto, a proposta se estendeu em veicular matérias de outros cunhos. Disponível em https://catracalivre.com.br/quem-somos/. Acesso em: 11 dez. 2020.

5 Além do site selecionado para análise, as manifestações também podem ser vistas no Portal UOL (https://noticias.uol.com.br/politica/ultimas-noticias/2020/04/19/pro-bolsonaro-e-contra-doria-sp-tem-2protestos-contra-isolamento-em-24-h.htm), no site da Folha de S. Paulo (https://www1.folha.uol.com.br/poder/2020/04/carreata-em-sp-perde-forca-volta-a-atacar-doria-e-pedefim-do-isolamento-social.shtml) e no Portal Globo (https:/g1.globo.com/sp/saopaulo/noticia/2020/05/31/avenida-paulista-tem-ato-e-marcha-contra-o-fascismo-e-a-favor-dademocracia-diz-pm.ghtml). Acesso em: 21 abr. 2021.

${ }^{6}$ De acordo com dados do Ministério da Saúde, até o dia 5 de março de 2021, foram contabilizados mais de 411 mil mortes e mais de 14, 5 milhões de casos confirmados. Disponível em: https://covid.saude.gov.br/. Acesso em: 5 mai. 2021. 


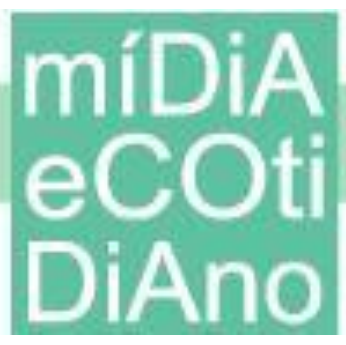

ocorridas em São Paulo no dia 11 de abril de 2020, que tiveram início na avenida Paulista e se estenderam por outras vias públicas da cidade. O movimento solicitou o fim da quarentena, o impeachment do governador do Estado de São Paulo, João Doria ${ }^{7}$ (PSDB), um dos desafetos do presidente Jair Bolsonaro, e a retomada das atividades produtivas, a despeito do crescimento do número de mortes e infecções. A escolha do site Catraca Livre procede porque o acontecimento foi construído a partir de narrativas diversas, ou seja, além do texto jornalístico, houve a veiculação de vídeos extraídos de redes sociais que puderam evidenciar o descaso público praticado por populares quanto à doença. No caso em questão, o site recorreu às postagens de vídeos que apresentaram o deboche e o escárnio praticados por pessoas anônimas diante da pandemia.

O vírus da Covid-19 foi identificado na China ainda em 2019 e ataca principalmente o aparelho respiratório, mas compromete também o funcionamento de outros órgãos, tecidos e sistemas, ainda mais quando o paciente tem comorbidades como pressão alta, diabetes e doenças autoimunes. Para a Organização Mundial da Saúde (OMS), como ainda não havia vacinas ou medicamentos específicos para o combate à doença ou ao vírus, a medida mais eficaz adotada para conter a infecção e manter o atendimento médico-hospitalar minimamente satisfatório foi, entre outras medidas, manter a higiene das mãos, usar máscaras faciais, adotar a quarentena e fazer isolamento físico. A medida suspendeu grande parte das atividades do comércio e da indústria e sugeriu evitar aglomerações em parques, praças e outros espaços públicos.

Mesmo provocando traumas na economia, a prática de quarentena foi adotada por muitos países, inclusive, pelo Brasil. Entretanto, no país, as políticas de isolamento não foram realizadas de modo plenamente eficaz. O descompasso político no enfrentamento da pandemia pelos governos federal, estaduais e municipais resultou em um alto índice de morte de brasileiros e brasileiras, foram mais de 400 mil vidas perdidas

\footnotetext{
${ }^{7}$ Durante o segundo turno das eleições de 2018, João Doria manifestou apoio ao então candidato à presidência do Brasil, Jair Bolsonaro. O clima amistoso entre ambos começou a ruir depois do decreto de pandemia pela OMS. Enquanto Doria se posicionou pela necessidade de realizar a quarentena, Bolsonaro se posicionou contra a adoção da suspensão das atividades. Além disso, pelo destaque obtido por Doria durante a pandemia, há tratativas de que ele seja candidato ao Executivo nacional nas eleições de 2022, o que o tornaria um adversário significante na campanha de reeleição de Bolsonaro. Disponível em: https://www.terra.com.br/noticias/brasil/politica/doria-e-mandetta-se-unem-em-frente-antibolsonaristaem-2022,0259783456d99cdb53485d41b2bf8111ai78h2o9.html. Acesso em: 25 nov. 2020.
} 


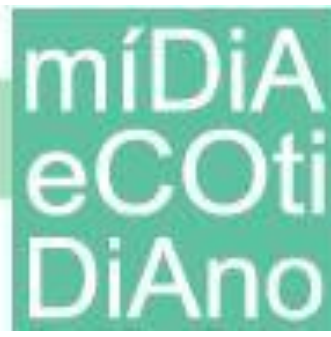

até a última versão deste artigo, no fim de abril de 2021. Populações de países como Itália e China ficaram confinadas em casa por mais de dois meses, sendo permitida a saída apenas para o uso de serviços essenciais como mercado, farmácia e hospital. Todavia o próprio presidente Jair Bolsonaro, em seu perfil no Twitter, questionou o isolamento porque poderia comprometer o sistema financeiro do país com a paralisação do setor produtivo $^{8}$. A preocupação maior do presidente era o retorno das atividades produtivas em detrimento da assistência às populações mais suscetíveis e carentes e na busca de vacinas. Em seu primeiro discurso após o início da pandemia, Bolsonaro desdenhou da potência de infecção e morte causadas pelo novo vírus ao fazer afirmações levianas (AMARAL, 2021) e, nos meses seguintes, ele também incentivou o uso de medicamentos que não apresentaram respaldo científico no combate e tratamento da Covid-19.

A partir dessas considerações, o artigo defende que o conceito de banalidade do mal é uma abordagem adequada para o caso em questão, na medida em que trata da existência de sujeitos convencionais que não demonstraram o que Arendt define como reflexão política.

\section{Quadro teórico-metodológico}

O ano de 2020 deixou rastros à posteridade por conta da pandemia do novo coronavírus, motivo que levou milhões de pessoas à morte e ao isolamento físico e fez potências como Estados Unidos e China virem suas projeções econômicas despencarem vertiginosamente. Foram reinventadas outras formas de sociabilidades e comunicação, outras estratégias de convivência e compartilhamento de espaços, bem como práticas de consumo e logísticas se intensificaram no comércio digital.

Por esse caminho, tanto a pandemia quanto os protestos - cujas narrativas são analisadas neste artigo - podem ser lidos como um acontecimento pela ótica de Arendt (2018). De acordo com a autora, os acontecimentos são fatos que ocorrem e que rompem com o cotidiano. Ela traz essa ideia ao desenhar as origens do totalitarismo na Europa,

\footnotetext{
${ }^{8}$ Em visita a Boa Vista, capital do estado de Roraima, ele gravou a convocação à manifestação no dia 15 de março de 2020, contrariando as medidas protetivas apresentadas por órgãos competentes como evitar aglomerações. Disponível em: https://twitter.com/jairbolsonaro/status/1236309849673289728. Acesso em: 29 mai. 2020.
} 


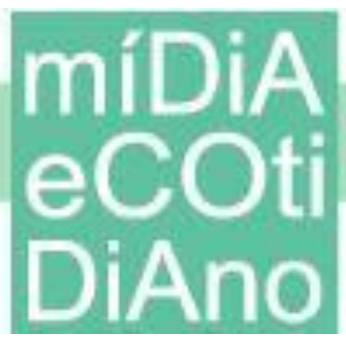

pois a incidência desse regime estilhaçou a cadência entre o passado e o futuro, principalmente no que tange assuntos sobre política. Obviamente que os fatos não precisam alcançar a magnitude dos governos totalitários para que sejam considerados acontecimentos, mas se apresentam diante dos nossos olhos na intenção de organizarem a vida social, pública e, até mesmo, privada. Em compasso com essa posição, França (2012), que se apropriou das discussões de Louis Quéré que, por sua vez, se baseou em Arendt, aponta que "O acontecimento o é porque interrompe uma rotina, atravessa o já esperado e conhecido, se faz notar por aqueles a quem ele acontece" (FRANÇA, 2012, p. 13). Entretanto, o acontecimento não se limita apenas à percepção dos fatos, mas se prolonga enquanto uma proposta reflexiva acerca do passado, na organização do presente e na projeção do futuro; e as práticas midiáticas organizam e, também, são organizadas pelos acontecimentos. Assim, há a presença da imprensa e de outras práticas midiáticas na organização e elaboração desses fatos para que o acontecimento permaneça em atividade ou perca fôlego para circular.

De acordo com França (2012), o acontecimento se manifesta enquanto uma existência e, para que não se limite a ser mero fato, precisa ser constituído pela linguagem. As práticas do jornalismo tornam-se, desse modo, empenhos eficientes para esse feito. Quando o acontecimento é constituído pela linguagem, ele passa a ser reverberado dentro do bojo social promovendo outras leituras e fomentando outros acontecimentos. Assim, um acontecimento não se limita apenas à sua ocorrência, mas é atravessado e construído pelos valores que estão em circulação, além de construir outras realidades e permanecer em atividade por tempo indeterminado. Como menciona França (2012), os acontecimentos dizem a nós mesmos como somos e nos comportamos. Esta reflexão sobre os acontecimentos oferece base para acreditar que as manifestações relatadas pelas práticas do jornalismo se tornaram vitrines para ilustrar o negacionismo e, também, outras concepções da banalidade do mal que estão presentes. Se há negação da ciência, por exemplo, é possível que haja a crença em valores que não sejam coletivos sendo compartilhados no espaço público enquanto condição moral, como as paixões privadas e os signos narcísicos que impedem a ação política.

Por política, o texto se apoia no entendimento apresentado por Arendt (2018). Ela compreendeu que a política não está relacionada com as propostas de um determinado 


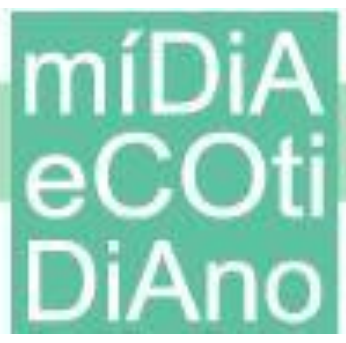

regime governamental, mas com a condição de sujeitos livres proporem soluções em concerto no espaço público de tal forma que sejam contemplatadas demandas que promovam a pluralidade, a visibilidade, a comunicação e a liberdade, a despeito de haver diferentes posicionamentos e pensamentos.

Destarte, se por meio do jornalismo estão visíveis as manifestações ocorridas no dia 11 de abril que prezaram pela retomada das atividades produtivas, que questionaram o isolamento e que promoveram a paixão pela figura do presidente é porque, em alguma medida, esses desejos fazem sentido e são clamados por certas parcelas da população, mesmo que essas demandas não apresentem cunho político, pelo prisma de Arendt. O discurso jornalístico não é uma mera ponte entre o fato e a sociedade, tampouco é apenas uma janela de onde se observa o mundo, mas uma condição de percepção sintomática dos valores que estão em reverberação.

O pensamento de Arendt sobre a banalidade do mal surgiu após a autora acompanhar o julgamento de Adolf Eichmann, em Jerusalém, em 1961, depois de ele ter sido sequestrado da Argentina, onde se asilou ao final do regime nazista na Alemanha. Ele se safou do julgamento de Nuremberg que condenou, inclusive à pena de morte, alguns integrantes do Partido Nazistas por crime contra o povo judeu ${ }^{9}$. Eichmann era responsável pela logística dos trens que transportavam pessoas aos campos de concentração, de onde eram remetidas à morte. De acordo com a filósofa (ARENDT, 1999), ele era um sujeito convencional, ambicioso, porém medíocre e limitado do ponto de vista da intelectualidade e da reflexão política.

Mesmo dias antes da força-tarefa de sequestro até o dia do julgamento, Eichmann foi desenhado pela comunidade e autoridades judaicas como um monstro, uma figura atroz dotada de extrema agressividade; para tanto, ele permaneceu dentro de uma gaiola de vidro durante todo o julgamento para que a sua segurança e a da plateia pudessem ser garantidas. Entretanto, Arendt afirmou que não encontrou uma figura exatamente repugnante ou abominável, mas estava diante de uma pessoa ordinária e sem grandes expressividades cognitivas.

\footnotetext{
${ }^{9} \mathrm{O}$ fato de Arendt considerar que os crimes cometidos pelos nazistas foram crimes contra à humanidade $\mathrm{e}$ não apenas contra os judeus rendeu a ela rusgas com a comunidade judaica, mesmo ela sendo judia.
} 
Eichmann era mais um burocrata que desenvolvia suas atividades laborais sem as devidas reflexões e criticidade. Torna-se difícil acreditar que, pelo ofício que desempenhava, ele não sabia que despachou grandes contingentes de pessoas à morte. $O$ que Arendt (1999) aponta é que Eichmann não percebeu as consequências do seu ato e que a debilidade dele em pensar politicamente se tornou próspera para que ela considerasse o mal como sendo banal. Como apresenta Bernstein (2018), o mal é banal não porque é irrelevante, mas porque é exercido por pessoas triviais em práticas do dia a dia como as atividades de trabalho. Assim, há indícios para pensar que as manifestações nas ruas de São Paulo podem ser compreendidas na perspectiva da banalidade do mal se considerarmos que foram organizadas por pessoas que se ausentaram de pensar politicamente o espaço público, ao promoverem aglomeração e desdenharem do potencial de letalidade do vírus. Para Arendt (2002), pensar politicamente é um rito constante e que necessita de alargamento da mente para compreender o mundo que cerca a humanidade contemplando a pluralidade e as melhores ações dentro do espaço público. Eichmann, ao juízo de Arendt, não promoveu essa estratégia por se limitar à própria condição de um reprodutor laboral. Dentro da realidade pandêmica brasileira torna-se irrefutável considerar que bloquear o trânsito de ambulâncias, promover a adoração ao presidente e negligenciar a ciência e as medidas sanitárias, como fizeram os manifestantes da avenida Paulista, sejam outras configurações de um mal banal diante da magnitude da pandemia.

Às perguntas feitas pelos promotores no dia do julgamento, Eichmann respondia com frases prontas, sem grandes elaborações. Ele repetia com muita frequência que era inocente e que nunca cometera quaisquer crimes contra os judeus porque apenas cumpria ordens. Pela visão da autora, Eichmann não seria considerado um monstro, "mas era difícil não desconfiar que não era um palhaço" (ARENDT, 1999, p. 67). Conforme o próprio afirmou, ele não tinha absolutamente nada contra judeus e, inclusive, conviveu com uma família judia na infância. Além disso, constantemente afirmava que estava cumprindo ordens e obedecia aos pedidos vindos de patentes superiores à sua que, segundo ele mesmo, seria mais um motivo para ratificar sua inocência diante do Holocausto. Para Arendt, Eichmann era um funcionário dotado de uma cegueira obediente e que não conseguia avançar para além dessa qualidade (ARENDT, 1999). 
O comportamento dele frente às atrocidades cometidas foi um divisor de águas para Arendt nas elaborações sobre o mal. Segundo descreve Bernstein (2018), a Solução Final $^{10}$, que levou milhões de pessoas à morte, foi um acontecimento bárbaro, todavia, nem todos os seus envolvidos o eram, como foi o caso de Eichmann. Arendt (2012) percebeu que o regime totalitário, além de ter como base o mal radical ${ }^{11}$, isto é, promover a destruição dos direitos universais conquistados principalmente nas revoluções burguesas do século XVIII, também encontrou forças na ocorrência do mal banal. O mal também pode ser encontrado e reproduzido por pessoas que não apresentam destaques públicos e que não são dotadas de grande representatividade no meio em que atuam. Eichmann é um sintoma da destruição do espaço público e da ação política por se ausentar, em grande medida, de pensar politicamente. Embora os fatos aqui analisados não tragam referências à atuação profissional de um burocrata que executa com exímia obediência seu trabalho, eles explicitam pessoas convencionais que se abstêm de pensar politicamente até mesmo em situações delicadas como a pandemia, que requer cuidados e um comprometimento coletivo para viabilizar melhores soluções.

Além disso, os grupos obedeceram cegamente a suas paixões e às vontades de seus semelhantes ao promoverem atos públicos em São Paulo. Atender a pedidos de manifestações que ocasionam aglomerações é agir de modo obediente sem a devida reflexão das consequências políticas e, também, sanitárias dos próprios atos. Arendt (2012) observava com muita cautela os pensamentos e movimentos ideológicos por considerá-los como condições refratárias de liberdade e limitadores de reflexão.

Esse entendimento pode ser aplicado às pessoas que promoveram em praça pública a volta das atividades produtivas durante a condição pandêmica. O retorno das atividades produtivas e laborais implicaria destinar pessoas à morte ou às incertezas de atendimento em hospitais à beira do colapso para o tratamento de uma doença, até então, muito desconhecida. Assim, o pedido de retorno ao labor, dentro daquela realidade, não

\footnotetext{
${ }^{10}$ Criada pelos oficiais Reinhard Heydrich e Heinrich Himmler, a Solução Final se propunha a exterminar os judeus da Europa. O extermínio foi ao encontro do desejo de Adolf Hitler, que aprovou a iniciativa. As mortes começaram a ser executadas a partir de fuzilamento, entretanto, por uma questão de economia e eficiência, o método adotado foi de asfixia em câmera de gás.

${ }^{11}$ Em Origens do totalitarismo, Arendt (2012), apoiada em Immanuel Kant, acredita que haja uma raiz para a ocorrência do mal. Esta ideia não é totalmente descartada, mas recebe outros contornos quando reconhece em Eichmann outras faces do mal.
} 


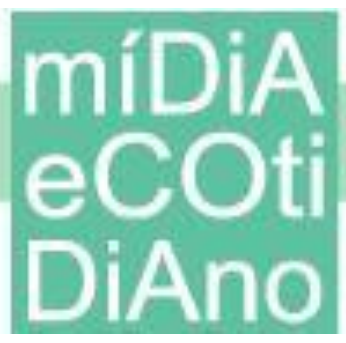

pode ser compreendido como ação política, nos termos arendtianos. A intenção deste artigo não é de equiparar o relato de Arendt sobre Eichmann à realidade pandêmica brasileira, até porque os acontecimentos ocorrem em contextos distintos. Entretanto, a banalidade do mal se coloca como uma chave explicativa para entender como o mal banal pode ser reproduzido por qualquer sujeito, a despeito da realidade enfrentada, desde que ele se abstenha de pensar politicamente. Se durante o Holocausto o mal banal foi percebido em figuras como Eichmann, na atualidade, ele pode ser encarado nas ruas sem o pudor de demonstração, trazendo em comum em ambas as situações a irreflexão (thoughtlessness).

O pedido de retorno ao trabalho também pode contribuir para as demonstrações do mal banal na atualidade. Conforme apresentou Arendt (2018), o trabalho e as atividades laborais dentro da vida activa (a vida completa do sujeito incluindo aspectos públicos e privados) não apresentam sentido político, apenas se limitam a atender à necessidade do sujeito, isto é, o trabalho pertence a movimentações fundamentais para a manutenção da vida enquanto condição biológica e metabólica e não avança para a condição política justamente porque não promove a liberdade. Aos sujeitos que reconhecem na reprodução da vida associada ao trabalho um valor político, Arendt (2018) denominou como animal laborans, pois apresentam comportamentos mais alinhados ao extinto de sobrevivência do que à busca pelo consentimento para o fomento da ação política. Para Arendt, a liberdade é um dos pressupostos para a edificação da ação política e uma das condições fundamentais para a reflexão sobre a vida pública. Com base nessas contribuições, este artigo apresenta a seguir uma reflexão sobre as manifestações contra a suspensão das atividades produtivas durante a pandemia, na perspectiva do conceito de banalidade do mal.

\section{Desenvolvimento: o mal banal em ações contemporâneas}

$\mathrm{Na}$ contemporaneidade, o mal banal não se encontra associado exatamente às práticas totalitárias estudadas por Hannah Arendt pelo exercício de uma função laboral. Os acontecimentos relatados nesta pesquisa revelam: a incapacidade dos manifestantes de arquitetar o espaço público para responder demandas mais amplas, a promoção do negacionismo científico e o desejo pelo retorno precoce às atividades produtivas, entre 


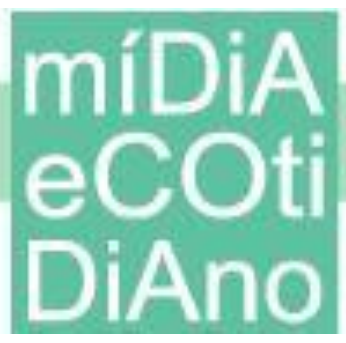

outros aspectos. Além disso, violam a dignidade humana quando demonstram uma ausência do luto pelos mortos que foram vítimas da Covid-19, como evidenciam as matérias do site selecionado.

Na tarde do dia 11 de abril de 2020, um grupo de pessoas ocupou as ruas em São Paulo, começando na avenida Paulista, para se manifestar contra as medidas protetivas de combate ao vírus, como o isolamento físico. $\mathrm{O}$ evento foi noite adentro, passando por outras vias públicas da cidade. As medidas de isolamento sugeridas pela OMS são propostas políticas sobre o prisma arendtiano porque constroem possibilidades de modo mais satisfatório para a organização do espaço público.

As manifestações em São Paulo podem ser consideradas um acontecimento, pela ótica de França (2012) e Arendt (2018), por romperem o esperado enquanto práticas sanitárias dentro de um estado de exceção imposto pela pandemia. O rompimento também se realiza porque fere os propósitos de conjectura da ação política sugerida por Arendt (2018) por não promover o desenvolvimento do espaço público em ação coletiva. De acordo com França (2012), “acontecimentos acontecem em nossa experiência - e falam dessa experiência. Retratam quem somos, como vivemos" (FRANÇA, 2012, p. 20). Além de protestarem contra as medidas protetivas, os manifestantes trazem outras demandas, como o apoio e solidariedade a Jair Bolsonaro, acreditando que a quarentena poderia ser prejudicial à economia do país e, por isso, o desejo de relaxamento das medidas de isolamento.

Com o título e linha fina, respectivamente, "Bolsonaristas tiram sarro das 1.233 mortes por coronavírus no Brasil/Apoiadores do presidente que pedem o fim do isolamento social levaram um caixão à Paulista, em São Paulo, e dançaram em aglomeração”. Na contramão das medidas de segurança sanitária, o texto apresenta como os manifestantes construíram um cenário de escárnio e de negacionismo.

Apesar da pandemia do novo coronavírus e das recomendações científicas da Organização Mundial da Saúde (OMS) para que as pessoas fiquem em casa, em isolamento social, os bolsonaristas querem que o povo contrarie a ciência (CATRACA, 2020a).

Essa passagem da matéria evidencia a ausência do que Arendt entende por pensamento político uma vez que promover aglomerações para o fim da quarentena é uma 


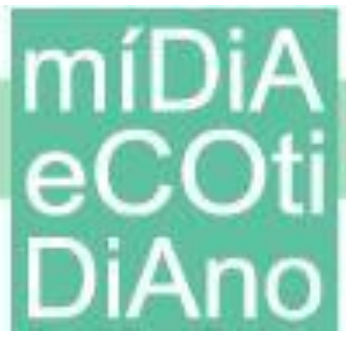

medida que esfarela o debate público, porque não contribui para o desenvolvimento da ação em conjunto. Para além disso, outro trecho da matéria indica a existência das paixões privadas como demanda moral levada ao espaço público, conforme mostra texto relativo ao vídeo da encenação do enterro de Doria:

Nas imagens que circulam pelas redes sociais, o grupo de bolsonaristas em questão levanta um caixão e imita aquele meme em que os coveiros dançam com caixão nos ombros, celebrando a "morte do governo Doria". O governador de São Paulo tem tomado medidas duras com relação à quarentena, a fim de salvar o maior número de vidas possível no estado. Em tempos em que 1.223 pessoas já morreram no Brasil (fora os números subnotificados), essa dancinha na Paulista com um caixão é o mais claro sinal de deboche para com a vida (CATRACA, 2020a).

Não há a obrigatoriedade a qualquer cidadão, paulistano ou não, de cultivar simpatia pelo governador João Doria. Entretanto, o desejo por sua morte ou afastamento é motivado pela decisão do governador de decretar a suspensão das atividades produtivas e por ter se tornado um dos desafetos de Bolsonaro naquele momento. Os grupos de manifestantes que ocuparam o espaço público a partir dessas frentes não evoluíram para a construção da ação política; ao contrário, cravaram ainda mais hiatos porque esses atos são originados a partir de paixões privadas e da ausência de pensamento alargado que vise a saídas melhores para a movimentação política.

Para além dos pontos apresentados, para os manifestantes, o isolamento promulgaria a "ditadura da Covid-19", pois limitaria a liberdade de locomoção dos cidadãos e traria prejuízos ao setor produtivo do Brasil. Acreditar que as medidas de isolamento físico sejam compreendidas como ditadura é uma concepção antipolítica porque não reconhece as práticas de organização do espaço público, além de alimentar a condição fantasiosa de que as medidas sanitárias são concebidas enquanto propostas ideológicas. Não obstante, simulando o enterro do governador de São Paulo, os manifestantes dançaram ao som de música alta trazendo um caixão nos ombros. A dança e a música executadas imitavam um dos memes mais reproduzidos e divulgados na internet nos tempos de quarentena, o chamado meme do caixão. Esse meme, na verdade, encena o cortejo fúnebre em Gana, na África. Há um serviço funerário naquele país em que homens contratados levam o caixão nos ombros até o cemitério ao som de música e 


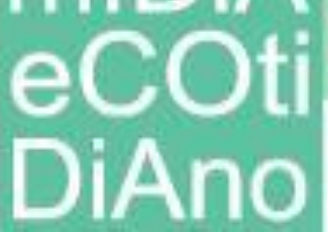

muita animação. Imitando o cortejo ganense, durante a manifestação na avenida Paulista, houve o desejo da morte de João Doria e de amenizar os efeitos da pandemia, mesmo refutando que, naquele momento, o país contabilizava 1.223 óbitos. Aos gritos, os manifestantes ainda disseram palavras de ordem como "Fora, Doria".

Figura 1 - Manifestantes carregando caixão na avenida Paulista

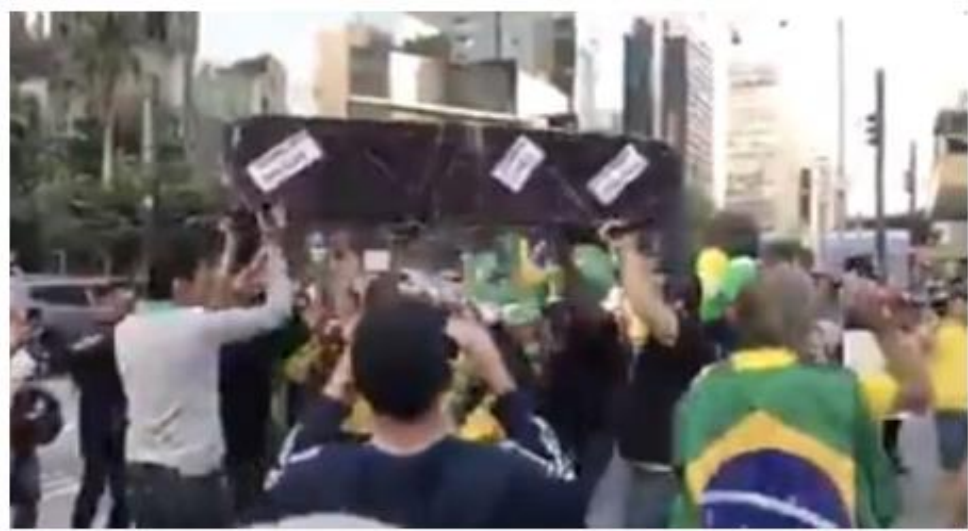

Crédito: Reprodução/Twitter

Bolsonaristas debocham das mortes ocorridas no Brasil pelo coronavírus

Fonte: Captura de tela elaborada pelo autor ${ }^{12}$.

De acordo com as vozes que participaram do ato, Bolsonaro sofre perseguição ideológica e política por parte de governadores e prefeitos que não apresentam a mesma linha de atuação dele. Os manifestantes da figura 2, além de demonstrarem simpatia ao presidente brasileiro, também afirmaram ser contra o aborto, contra o governo de João Doria, contra a quarentena e contra a suspensão das atividades produtivas, ou seja, um leque difuso de reinvindicações.

12 Disponível em: https://catracalivre.com.br/cidadania/manifestantes-pro-bolsonaro-travam-ambulanciasem-ato-na-paulista/. Acesso: 20 nov. 2020. 
Figura 2 - Manifestação na avenida Paulista em carro de som

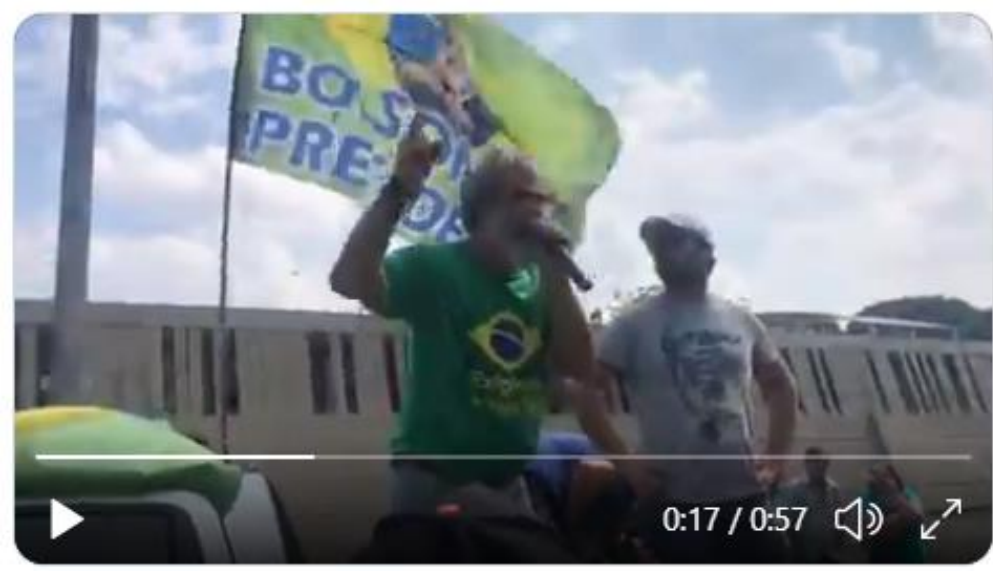

1:49 PM $\cdot 11$ de abr de 2020

Fonte: Captura de tela elaborada pelo autor ${ }^{13}$.

Se, por um lado, promover a chacota em praça pública em consonância com a frivolidade da cerimônia africana descontextualizada com as mortes causadas pelo novo coronavírus é perverso, por outro lado, desrespeitar o isolamento em obediência às paixões privadas e promover aglomerações fortalecem a ideia da banalidade do mal de forma explícita e sem receios de demonstrações. Além disso, os manifestantes desmerecem o sentimento de luto, não apenas de brasileiros, mas de todos aqueles que foram afetados pelas mortes causadas pela Covid-19 no mundo.

Não possibilitar o luto, segundo Butler (2006), é agredir o espaço político. De acordo com a autora, o luto não é apenas uma condição privada e individual em que o sujeito se abstém do contato social para experienciar a dor e a saudade, mas é um movimento político e coletivo. A vulnerabilidade à dor e à morte une grupos e sujeitos, os colocam em pé de igualdade a qualquer outro sujeito ou grupo da face da Terra, e o luto costura as relações complexas de dependência e de responsabilidade com as demais pessoas com as quais é compartilhado o espaço público. Mesmo reconhecendo que algumas vidas são privadas de vivenciar o luto enquanto uma manifestação política, justamente pela precariedade em que se encontram, Butler (2006) considera que essa prática seria desumana porque não reconhece o compromisso político e ético do luto com

\footnotetext{
${ }^{13}$ Disponível em: https://catracalivre.com.br/cidadania/manifestantes-pro-bolsonaro-travam-ambulancias-
} em-ato-na-paulista/. Acesso: 20 nov. 2020. 
a sociedade. Assim, o mal banal nas ações identificadas no contexto brasileiro, além de ser escancarado, restringe princípios elementares como o luto enquanto ação política, e foi justamente essa prática que pode ser observada no conteúdo das matérias.

Quanto ao entendimento de Arendt sobre ação política, as manifestações em São Paulo podem ser compreendidas como sintoma de fragmentação pelas consequências das atitudes dos manifestantes. Conforme apresenta outra matéria selecionada (CATRACA LIVRE, 2020b), ainda na avenida Paulista, três ambulâncias foram impedidas de passar, sendo o ato registrado pelas imagens amadoras por um manifestante. $\mathrm{O}$ vídeo, possivelmente publicado pelo sujeito que aparece nas figuras 3 e 4 trajando a camisa oficial da seleção brasileira de futebol, ao que indica, sente-se orgulhoso de interromper o trânsito da avenida Paulista quando afirma "Paramos a avenida Paulista, vamos parar São Paulo. Fora, Doria!”. Além disso, como apresenta a matéria, os manifestantes também eram contra "TV Globo, Band [TV Bandeirantes] e a China” (CATRACA LIVRE, 2020b). Obstruir a passagem de ambulâncias, em qualquer condição da vida cotidiana é um movimento agressivo e, dentro de um estado pandêmico, torna-se mais grave por uma questão de negligência sanitária à saúde pública.

\section{Figura 3 - Manifestante na Paulista impedindo o trânsito}

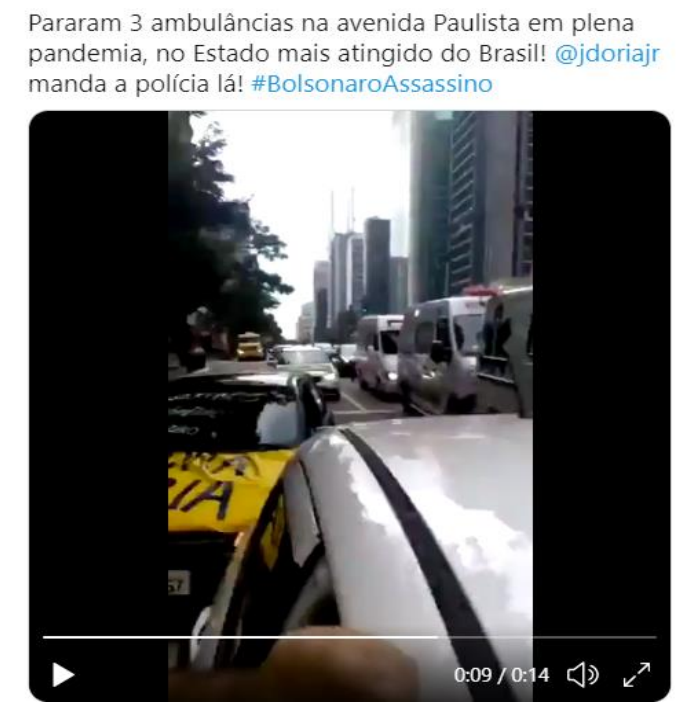

Fonte: Captura de tela elaborada pelo autor ${ }^{14}$.

\footnotetext{
${ }^{14}$ Disponível em: https://catracalivre.com.br/cidadania/manifestantes-pro-bolsonaro-travam-ambulancias-
} em-ato-na-paulista/. Acesso: 20 nov. 2020. 
Figura 4 - Manifestante na paulista ${ }^{15}$

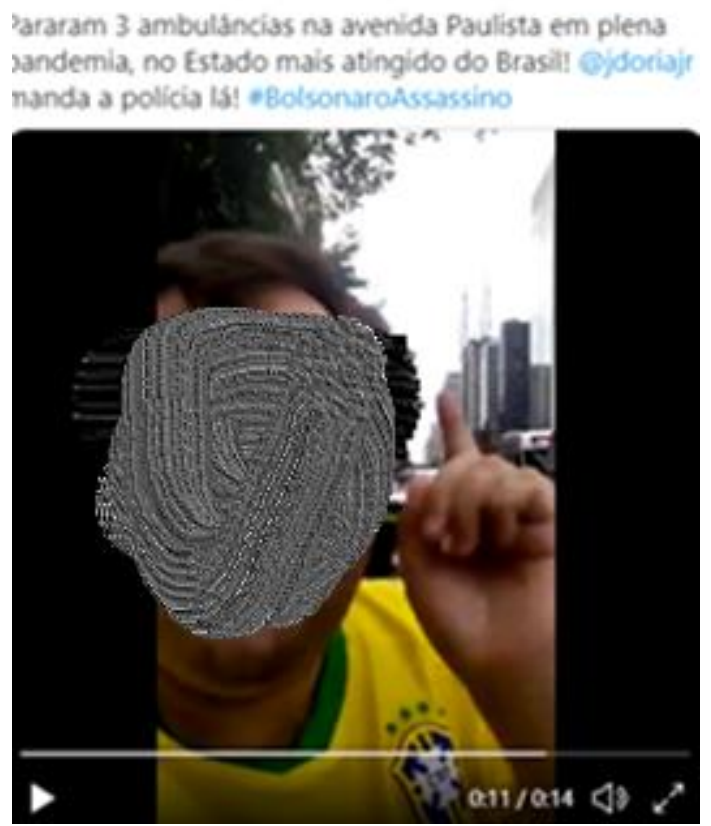

Fonte: Captura de tela elaborada pelo autor ${ }^{16}$.

Produzir e disseminar sem qualquer estreiteza o vídeo em que as ambulâncias são proibidas de circular dentro daquela realidade é prezar pela morte, suportar que algumas vidas podem ser matáveis e ratificar que, assim, são desprovidas de sentido público e político. Agamben (2010) diagnosticou que algumas existências podem ser expoentes da vida nua, ou seja, são vidas despossuídas de direitos e que quando morrem não promovem dolo ou responsabilidade, são indiferentes dentro do espaço público, isto é, são descartáveis. A atitude do sujeito do vídeo veiculado pela matéria, além de suportar o mal banal em ações contemporâneas, ainda desqualifica a vida e a arremessa aos caminhos da morte. Por outro lado, é importante notar que, a partir de outras medidas, o presidente Jair Bolsonaro é também responsável pelas mortes ao negar a ciência e não oferecer assistência complacente à população quando desdenha dos óbitos ocorridos ou responsabiliza a imprensa e seus adversários de perseguição política. A banalidade do mal dentro da poética pandêmica oferece suporte para alastrar o cenário catastrófico em

\footnotetext{
${ }^{15}$ A figura 4 foi alterada para preservar a identidade do homem retratado.

${ }^{16}$ Disponível em: https://catracalivre.com.br/cidadania/manifestantes-pro-bolsonaro-travam-ambulanciasem-ato-na-paulista/. Acesso: 20 nov. 2020.
} 


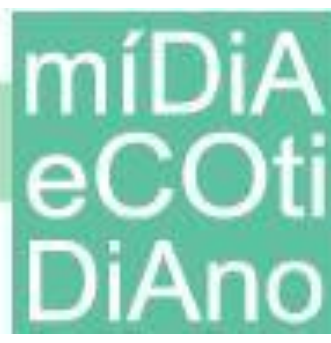

que o Brasil se encontra, uma vez que não há políticas públicas eficientes para o enfrentamento da doença, na época da manifestação não havia sequer um plano nacional unificado de vacinação.

Aquele contingente de pessoas não conseguiu alcançar a ação política pelas pautas suscitadas, até porque há uma miscelânea de reivindicações antidemocráticas como a extinção de emissoras de televisão e questões que ferem o rito diplomático por ofender o governo chinês. Enquanto Arendt (2004) acreditou que Eichmann apenas obedecia às ordens superiores, os manifestantes do protesto obedeceram apenas às próprias convicções partidárias e suas paixões privadas. A sensação de Arendt sobre o funcionário nazista, nesse sentido, ajuda a expressar o sentido da manifestação em São Paulo. Sua conspícua superficialidade, não sendo pessoas demoníacas ou monstruosas, mas pessoas comuns, revela "a única característica notória (...) a irreflexão" (ARENDT, 2002, p. 5-6).

Provavelmente, nenhum desses sujeitos da avenida Paulista é algum criminoso ou contraventor sanguinário, mas são pessoas que se ausentaram de pensar politicamente. A obediência, exercida de modo em que é desprovida de criticidade e razão, agride o espaço público e político, diferentemente do consentimento, que é fruto da reflexão empreendida por cada indivíduo. Obedecer não é consentir, como aponta Ramos (2017):

[...] a equação que identifica o consentimento à obediência é uma falácia porque infantiliza os membros do corpo político ao transformálos em objeto de simples mando, eclipsando, assim, a exigência de um verdadeiro consentimento dirigido à organização, à autoridade ou à lei [...] (RAMOS, 2017, p. 77).

Para a autora, a obediência é agir em massa carecendo de autonomia, negando sua singularidade e seu histórico em nome de um contingente massivo. Pela visão de Ramos (2017), pessoas como Eichmann ofereceram suporte aos movimentos totalitários da primeira metade do século XX porque apenas obedeceram às regras impostas pelo sistema, e esse comportamento ofereceu sustentação para o desenvolvimento do mal banal. Com base nessa consideração sobre a oferta de suporte, o mal vigora como sendo banal porque é resultado da ausência da reflexão política e do descaso frente às organizações, leis e ações. Contestar a adoção do isolamento é suportar a banalidade do 


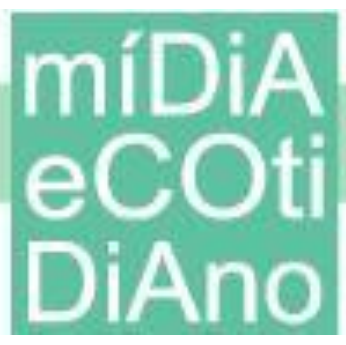

mal contemporânea e contribuir para a degradação do espaço político, além de promover o aumento de mortes e a provocar a superlotação em hospitais.

Além da abstinência de pensar politicamente, o suporte à banalidade do mal é fruto das paixões privadas. Nesse caso, as paixões não se enquadram no desejo de articular ações com o espaço público, mas se referem à associação com aspectos privados, longe das referências da ação política. Conforme aponta Assy (2016), as satisfações privadas não promovem o espaço político:

Ao comunicarmos nossos sentimentos, nossas satisfações e deleites desinteressados, explicitamos nossas escolhas e elegemos nossas companhias. A tentação de identificar deleite e satisfação exclusivamente com realizações pessoais ou com o concomitante contentamento material nas sociedades de consumo demonstra não só o empobrecimento da nossa capacidade de imaginar, mas o aniquilamento de nossa capacidade de ter aprazimento com algo que não traga consigo expectativas e interesses particulares (ASSY, 2016, p. 49).

$\mathrm{Na}$ intolerância de diálogos para promover a visibilidade de discursos e representação, a paixão dos manifestantes não avança para a discussão de saídas melhores para a organização do espaço público. A intenção de apagar a pluralidade de discursos e representações não gera ação política, mas incentiva valores de violência pelo silenciamento da diversidade de discursos e propostas, além de empobrecer os debates públicos. Essa não foi a primeira vez que apoiadores do presidente Jair Bolsonaro promoveram manifestações em seu nome. Em momentos críticos do seu governo, seus préstitos atendem às convocações feitas por WhatsApp ou pelas redes sociais por grupos que o apoiam. A atitude de obedecer cegamente aos pedidos sem reflexão, conforme Arendt (1999), é o exercício para o fomento do mal.

Demier (2020) aponta que, para a realidade política brasileira contemporânea desde o impeachment de Dilma Rousseff, em 2016, há indícios da normalização do mal. Pela observação de Demier (2020), é possível estabelecer que um acontecimento tem origem no passado, ou seja, experiências pretéritas oferecem base para a ocorrência de acontecimentos no presente. Apesar de o autor não utilizar o conceito de banalidade do mal, seu trabalho dialoga com esta discussão, na medida em que identifica o mal como normalizado enquanto prática moral e ética. Segundo Demier, depois do impedimento de 


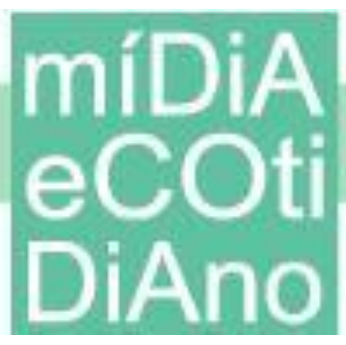

Dilma Rousseff, foi possível reconhecer a ascensão de movimentos de ultradireita e grupos interessados em desrespeitar os dogmas democráticos e da ação política de modo muito evidente.

Para contextualizar suas ideias, o autor trouxe à tona a tomada de poder por Napoleão Bonaparte na França, apresentada por Karl Marx na obra 18 de Brumário, em que a população assistiu ao golpe bonapartista e não reagiu ou ofereceu resistência ao movimento, presenciando-o de forma passiva. Dentro do contexto nacional, Demier (2010) afirma que o mal “(...) de tanto exibir a sua maldade, e de tanto ser apresentado como a mais pura encarnação do bem, pode ser gradativamente aceito acriticamente pelos sujeitos desprovidos de crítica" (DEMIER, 2020, p. 39). As pessoas mencionadas por Demier não estão distantes daquelas idealizadas pelo pensamento de Arendt que reproduzem, suportam a banalidade do mal e que também podem ser encontradas nas manifestações em análise pelas matérias veiculadas pelo site Catraca Livre. Se na época em que Arendt (1999) teceu a ideia de banalidade do mal a partir de um funcionário medíocre que obedecia às ordens no exercício da sua função, no atual cenário a inflexão política pode ser executada por qualquer sujeito a despeito da sua atividade laboral. Além disso, as reflexões de Demier (2010) auxiliam na análise dos acontecimentos em tela porque verifica-se que estes não ocorrem ao acaso, mas são frutos de outros acontecimentos pretéritos que se desenrolam na linha do tempo.

Quando não há a reflexão política, as portas estão abertas para manifestações do mal e, também, da violência. Arendt (1985) afirmou que a violência é o expoente da destruição do espaço político, ou seja, é sintoma do desarranjo público para articulações propostas em concerto. $\mathrm{O}$ entendimento de violência pensado por Arendt pode ser reconhecido no acontecimento relatado neste texto por ser uma demonstração tácita da ausência do pensamento político. Nesse caso, a violência é calcada em relações de cotidianidade e impessoalidade, praticada e contemplada nas estruturas e ações triviais do dia a dia como sintoma das relações estabelecidas por uma ordem histórica e social de dominação, ou pelas palavras de Žižek (2014), como sendo simbólico-social, isto é, dotada de tal espontaneidade do meio em que é praticada como o ar que se respira. Entretanto, as reflexões sobre a violência podem ser explicadas com mais profundidade em outra oportunidade de estudo. 


\section{míiA

\section{Considerações finais}

Observar a realidade pandêmica brasileira, pelo prisma da banalidade do mal, no âmbito das matérias do site Catraca Livre, mostrou-se uma atividade produtiva de reflexão. Ela trouxe a possibilidade de enxergar a olho nu, em praça pública, as condições de emergência do mal banal, durante a pandemia do coronavírus, no contexto brasileiro. Como um acontecimento não se limita ao fato, outras demonstrações puderam ser vistas no espaço público, tendo o jornalismo como mediador das realidades que se constituíram a partir das manifestações realizadas.

Os acontecimentos analisados aqui estão marcados pelo descaso e pela irrelevância da vida no espaço público, e a tessitura deles pela lente do jornalismo evidencia traços dos valores da fragmentação da ação política sem qualquer pudor. Os acontecimentos foram apresentados pelo jornalismo como práticas que se encontram em atividade, mesmo em momentos de exceção como os impostos pelo novo coronavírus.

Albert Camus, em seu livro A peste (2017), defende que o flagelo da praga sempre revela uma sociedade doente. Doente de um mal que, no caso analisado, atinge não apenas o corpo biológico, mas também o corpo político de sociedades fragmentadas. A pandemia, além de deflagrar crises de ordem sanitária, evidenciou também a crise política no sentido empreendido por Hannah Arendt. A arquitetura de ações que seriam propostas em concerto visando à promoção de liberdade, pluralidade, visibilidade e comunicação se esfarelou diante dos acontecimentos ocorridos durante a pandemia no Brasil. A irreflexão e as paixões privadas não tiveram pudor de invadir o espaço público, e a destruição do espaço político durante a pandemia não promoveu a união entre pessoas, mas o afastamento para a ação em concerto. Logo, as narrativas jornalísticas foram um espaço propício para evidenciar outras manifestações do mal banal, no espaço político.

\section{Referências}

AGAMBEN, Giorgio. Homo sacer: o poder soberano e a vida nua. Belo Horizonte: Editora UFMG, 2010.

AMARAL, Muriel Emídio Pessoa do. Discurso doente: Bolsonaro e covid-19. Revista ECCOM - Educação, Cultura e Comunicação, v. 23, n. 12, p. 540-553, 2021. Disponível em: http://unifatea.com.br/seer3/index.php/ECCOM/article/view/1326/1192. Acesso em: 21 abr. 2021. 
ARENDT, Hannah, Da violência. Brasília: Editora Universidade de Brasília, 1985.

ARENDT, Hannah. A condição humana. São Paulo: Forense Universitária, 2018.

ARENDT, Hannah. A vida do Espírito. O Pensar/ O Querer/ O Julgar, 5. ed. Tradução de A. Abranches, Cesar A. R. de Almeida, H. Martins. Rio de Janeiro: Relume Dumará, 2002.

ARENDT, Hannah. Eichmann em Jerusalém: relatos sobre a banalidade do mal. São Paulo: Companhia das Letras, 1999.

ARENDT, Hannah. Origens do totalitarismo. São Paulo: Companhia das Letras, 2012.

ARENDT, Hannah. Responsabilidade e Julgamento. Edição de Jerome Kohn. Trad. de R. Einchenberg. São Paulo: Companhia das Letras, 2004.

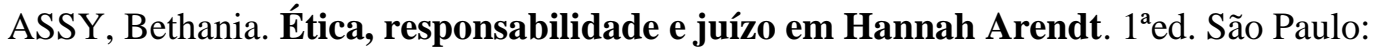
Perspectiva, 2016.

BERNSTEIN, Richard J. Why read Hannah Arendt now. Cambridge: Polity Press, 2018.

BUTLER, Judith. Precious life: the powers of mourning and violence. London: Verso, 2006.

CAMUS, Albert. A peste. Rio de Janeiro: Record, 2017.

CATRACA LIVRE. Bolsonaristas tiram sarro das 1223 mortes por coronavírus no Brasil. Site Catraca Livre. Disponível em: https://catracalivre.com.br/cidadania/bolsonaristas-tiram-sarrodas-1-223-mortes-por-coronavirus-no-brasil/. Acesso em: 11 dez. $2020 \mathrm{a}$.

CATRACA LIVRE. Manifestantes pró-Bolsonaro travam ambulâncias em ato na Paulista. Site Catraca Livre. Disponível em: https://catracalivre.com.br/cidadania/manifestantes-probolsonaro-travam-ambulancias-em-ato-na-paulista/. Acesso em: $11 \mathrm{dez} .2020 \mathrm{~b}$.

DEMIER, Felipe. O mal como normal: golpe, lei e direitos. In: BENJAMIN, Cid; DEMIER, Felipe; ARCARY, Valério. O ovo da serpente: a ameaça neofascista no Brasil de Bolsonaro. Rio de Janeiro: Mauad X, 2020, p. 37- 40.

FRANÇA, Vera. O acontecimento e a mídia. Galaxia, n. 24, p. 10-21, 2012.

RAMOS, Silvana de Souza. Hannah Arendt: não suportar o mal. Comunicações, v. 24, n. 2, p. 71-82, 2017. DOI: https://doi.org/10.15600/2238-121X/comunicacoes.v24n2p71-82.

ŽIŽEK, Slavoj. Violência: seis reflexões laterais. São Paulo: Boitempo, 2014. 